\section{Libya should stop denying scientific evidence on HIV}

SIR - We welcome Libya's recent decision to commute to life imprisonment the death sentences of five Bulgarian nurses and a Palestinian medic. All six were imprisoned for eight years on false charges of deliberately infecting children with HIV in the hospital where they worked. We also applaud the subsequent decision by Bulgaria's president to pardon and release the six immediately upon their extradition to Sofia.

We cannot accept, however, the Libyan government's continued denial of the scientific evidence in this case. That denial constitutes a barrier to establishing normal relations with the international medical and scientific community, from which assistance is urgently needed to upgrade Libya's healthcare system.

The 17 July announcement that Libya's Higher Judicial Council had commuted the death sentence to life imprisonment should have been accompanied by an explicit acknowledgement that the real cause of the outbreak was an accident stemming from insufficient infection controls and hospital safety precautions.

Indeed, the statements from Libya's prime minister and foreign minister, condemning the recent pardon, reiterating the original conspiracy charges and calling for the health workers to be re-imprisoned, shows that the final judicial and political decision-making process had little to do with the accumulated scientific evidence.

Despite pleas from more than 100 Nobel laureates (R. J. Roberts et al. Nature 444,$146 ; 2006$ ), the judiciary refused to allow independent scientific evidence to be heard during the trial.

In particular, the judiciary failed to take into account convincing findings that the HIV infection was present in the hospital before the arrival of the health-care workers (T. de Oliveira et al. Nature 444, 836-837; 2006). Similarly ignored was the concurrent outbreak of hepatitis $\mathrm{C}$ among the same population of children - a strong signal that they were picking up other blood-borne infections from the hospital.

Opportunities for contamination of medical materials are frequent in many hospitals in developing countries, and there is an urgent need to redress this situation by improving health-care policies and practices. The Libyan government wants to upgrade the standards of hygiene and care in its hospitals. With the cooperation of the international scientific and medical community, it could make Libyan hospitals a model for health care in the region and in the African continent.

Removing the obstacle of Libya's intransigence on the science in this case is essential to allow such cooperation to move forward. We call on the Libyan authorities to put this affair behind them, and to exonerate the six health-care workers.

Vittorio Colizzi`, Tulio de Oliveira†',

Richard J. Roberts;

*University of Rome Tor Vergata, Via della Ricerca

Scientifica, 00133 Rome, Italy

$\dagger$ South African National Bioinformatics Institute, University of Western Cape, Private Bag X17,

Bellville 7535, South Africa

New England Biolabs, 240 County Road, Ipswich,

Massachusetts 01938-2723, USA

This letter was also signed by:

Massimo Amicosante University of Rome Tor Vergata, Italy

Thomas Lehner Guy's Hospital, London, UK

Luc Montagnier World AIDS Foundation for Research and

Prevention, Paris, France

David Pauza University of Maryland, Baltimore, USA

Luc Perrin University Hospital, Geneva, Switzerland

Giovanni Rezza Istituto Superiore di Sanità, Rome, Italy

\section{Fires and climate linked in nineteenth century}

SIR - 'Atmospheric brown clouds', resulting from the burning of fossil fuels and biomass, have recently been reported to have a large effect on climate by altering the atmosphere's absorption of solar radiation (V. Ramanathan et al. Nature 448, 575-578; 2007).

Interestingly, even in the nineteenth century, some scientists held the view that tiny particles, or aerosols, produced from burning affect solar radiation, clouds and precipitation on a large scale - all factors that play into climate.

One of them, German geographer Alexander Freiherr von Danckelman, wrote an insightful but little-noticed paper on the topic (A. von Danckelman Z. österr. Ges. Met. (Meteorol. Z.) 19, 301-311; 1884).

After observing huge savannah fires in Africa during the 1880 s, von Danckelman reported that fires were accompanied by cumulus clouds, which subsequently spread and thinned, forming a brownish or blueish haze that persisted for days to weeks.

$\mathrm{He}$ argued against the view that fires were an immediate cause of rain showers, and proposed instead that they affected cloudiness and precipitation in an "indirect way”. He realized that by providing cloud condensation nuclei, fires might contribute to the fog and drizzle typical of the dry season. Estimating the amount of biomass burned in Africa each year, he concluded that savannah fires must have a major influence on largescale climate.

Von Danckelman's descriptions of haze produced from burning biomass and its effects on climate are surprisingly accurate. Although not every detail is correct, his theories anticipated many aspects of the current discussion on biomass burning and the effects of aerosols.

Sadly his work, published in French and German, is almost forgotten today and references to his papers are absent in current studies.

\section{Stefan Brönnimann}

Institute for Atmospheric and Climate Science, ETH Zurich, Universitätsstraße 16, $\mathrm{CH}-8092$ Zürich, Switzerland

\section{Climate: Sawyer predicted rate of warming in 1972}

SIR - Thirty-five years ago this week, Nature published a paper titled 'Man-made carbon dioxide and the "greenhouse" effect' by the eminent atmospheric scientist J. S. Sawyer (Nature 239, 23-26; 1972). In four pages Sawyer summarized what was known about the role of carbon dioxide in enhancing the natural greenhouse effect, and made a remarkable prediction of the warming expected at the end of the twentieth century. He concluded that the $25 \%$ increase in atmospheric carbon dioxide predicted to occur by 2000 corresponded to an increase of $0.6^{\circ} \mathrm{C}$ in world temperature.

In fact the global surface temperature rose about $0.5^{\circ} \mathrm{C}$ between the early 1970 s and 2000. Considering that global temperatures had, if anything, been falling in the decades leading up to the early 1970s, Sawyer's prediction of a reversal of this trend, and of the correct magnitude of the warming, is perhaps the most remarkable long-range forecast ever made.

Sawyer's review built on the work of many other scientists, including John Tyndall's in the nineteenth century (see, for example, J. Tyndall Philos. Mag. 22, 169-194 and $273-285$; 1861) and Guy Callender's in the mid-twentieth (for example, G. S. Callendar Weather 4, 310-314; 1949). But the anniversary of his paper is a reminder that, far from being a modern preoccupation, the effects of carbon dioxide on the global climate have been recognized for many decades.

Today, improved data, models and analyses allow discussion of possible changes in numerous meteorological variables aside from those Sawyer described. Hosting such discussions, the four volumes of the Intergovernmental Panel on Climate Change 2007 assessment run to several thousand pages, with more than 400 authors and about 2,500 reviewers. Despite huge efforts, and advances in the science, the scientific consensus on the amount of global warming expected from increasing atmospheric carbon dioxide concentrations has changed little from that in Sawyer's time.

Neville Nicholls

School of Geography and Environmental Science, Monash University, Victoria 3800, Australia 